\title{
EFEITOS DA VEGETAÇÃO NA VARIAÇÃO TÉRMICA DA CIDADE DE CURITIBA, PR
}

\author{
Luciana Leal ${ }^{1}$, Daniela Biondi² ${ }^{2}$ Antonio Carlos Batista ${ }^{3}$ \\ ${ }^{1}$ Eng $^{\text {a }}$. Florestal, Dr ${ }^{\mathrm{a}}$., COPEL, Curitiba, PR, Brasil - luciana_paisagem@yahoo.com.br \\ ${ }^{2}$ Eng $^{a}$. Florestal, Dr ${ }^{a}$., Depto. Ciências Florestais, UFPR, Curitiba, PR, Brasil - dbiondi @ufpr.br \\ ${ }^{3}$ Eng. Florestal, Dr., Depto. Ciências Florestais, UFPR, Curitiba, PR, Brasil - batistaufpr@ufpr.br \\ Recebido para publicação: 23/07/2013 - Aceito para publicação: 27/01/2014
}

\begin{abstract}
Resumo
Considerando que a distribuição das florestas urbanas e o zoneamento do uso do solo influenciam o clima local da cidade de Curitiba, este trabalho teve como objetivo analisar o efeito desses fatores na variação temporal e espacial da temperatura do ar nessa cidade. Os dados de temperatura foram coletados em quatro campanhas em períodos correspondentes às estações do ano em 2011, em 44 pontos de monitoramento em quatro transectos na malha urbana da cidade, por meio de miniabrigos meteorológicos com registradores modelo Hobo®. Nos quatro transectos, foram observadas diferenças térmicas entre os pontos de monitoramento nos períodos analisados. Para a temperatura máxima absoluta, as diferenças foram de até $5,8{ }^{\circ} \mathrm{C}$ no transecto sudoeste-nordeste, e para a temperatura mínima absoluta, de $4,6^{\circ} \mathrm{C}$ no transecto noroeste-sudeste. Mesmo nas estações do ano de mais baixas temperaturas, outono e inverno, foram encontradas diferenças térmicas, relacionadas ao calor antropogênico. As maiores temperaturas foram encontradas nos locais com maior intensidade de ocupação e atividades antrópicas, porém não nas áreas mais verticalizadas, enquanto as menores temperaturas foram encontradas nas regiões com maior quantidade de áreas permeáveis, concentração de remanescentes florestais ou espaços verdes públicos, confirmando a influência da densidade de construção e da presença de vegetação na variação das temperaturas na cidade de Curitiba.

Palavras-chave: Clima urbano; temperatura do ar; florestas urbanas; classes de densidade de ocupação.
\end{abstract}

\begin{abstract}
Effects of vegetation on thermal intra-urban variation of Curitiba - PR. Whereas the distribution of urban forests and zoning land use influence the climate of Curitiba city, this research aimed to analyze the effect of this factors in temporal and spatial variation of air temperature in this town. Temperature data were collected in four campaigns in periods corresponding to the seasons of the year in 2011, in 44 monitoring points in four transects in the urban mesh by mini-shields meteorological model with Hobo® loggers. In the four transects were found differences between the thermal monitoring points in the analyzed periods. For the absolute maximum temperature, differences were up to $5.8{ }^{\circ} \mathrm{C}$ in the northeast-southwest transect and the absolute minimum temperature of $4.6^{\circ} \mathrm{C}$ in the northeast-southwest transect. Even in seasons of lower temperatures, autumn and winter, thermal differences were related to anthropogenic heat. The highest temperatures were found in the regions with greater intensity of occupation and human activities, however not in the areas with verticalization, while the lowest temperatures were observed in regions with higher permeable areas, concentration of remaining forest and public green spaces. As result, it confirms the influence of building density and the presence of vegetation in the variation of temperature in the city of Curitiba.

Keywords: Urban climate; air temperature; urban forestry; class occupation density.
\end{abstract}

\section{INTRODUÇÃO}

A expansão das áreas urbanas é frequentemente associada com mudanças no clima local (OLIVEIRA et al., 2011), em especial em áreas pouco arborizadas e com maior densidade de construções (FEITOSA et al., 2011). 
O clima das cidades caracteriza-se por apresentar um fenômeno chamado de ilhas de calor urbano, com temperaturas mais elevadas quando comparadas ao seu entorno. Segundo Weng e Larson (2005), as ilhas de calor são anomalias térmicas caracterizadas pela elevação da temperatura em determinadas áreas quando comparadas a outras. As diferenças de temperatura são geralmente modestas, na média, menores que $1{ }^{\circ} \mathrm{C}$, mas ocasionalmente podem alcançar diversos graus, quando as condições urbanas, topográficas e meteorológicas são favoráveis ao desenvolvimento das ilhas de calor.

De acordo com Menon et al. (2008), o aquecimento das áreas urbanas é principalmente causado pelo calor antropogênico de veículos, indústrias, ar condicionado e de outras fontes de calor, e devido ao calor armazenado e irradiado pelas enormes e complexas estruturas urbanas, cuja rugosidade reduz a remoção do calor convectivo. Para King e Davis (2007), a razão de a cidade ser mais quente que os arredores vegetados vêm da diferença entre a energia adquirida e perdida em cada região. Durante o dia, nas áreas rurais, a energia solar absorvida próxima do solo evapora água da vegetação e solo. Assim, enquanto há ganho líquido de energia solar, isto é compensado com alguns graus pelo resfriamento evaporativo. Em cidades, onde há menos vegetação, as construções, ruas e calçadas absorvem a maioria do input de energia solar. Devido à cidade ter menos água, a perda (run-off) é maior nas cidades, porque os pavimentos na maioria não são porosos. Assim, o resfriamento evaporativo é menor, o que contribui para as altas temperaturas.

Uma das poucas metrópoles brasileiras que possui informações sobre clima urbano e ilhas de calor é Curitiba. No entanto, existem poucos estudos sobre a influência da distribuição da cobertura vegetal sobre o microclima urbano da cidade. Segundo Mendonça e Dubreuil (2005), o crescente processo de urbanização dessa cidade e de sua região metropolitana provocou a ocorrência de fenômenos como aumento da temperatura e poluição atmosférica.

A análise da evolução das condições climáticas mostra que, na cidade de Curitiba, a temperatura média tem aumentado progressivamente após a década de 1950 (NOGAROLLI, 2007). Rossi (2004), pela atualização do ano climático de referência, que consiste de um ano típico representativo de um determinado local considerando-se um período de no mínimo 10 anos consecutivos, encontrou em um período de 30 anos um aumento da temperatura de aproximadamente $0,6^{\circ} \mathrm{C}$, o que a autora relaciona ao acelerado crescimento urbano da cidade e sua conurbação com os municípios vizinhos, que ocorreu justamente nesse período.

Alguns estudos identificaram a presença de ilhas de calor na cidade de Curitiba, como os trabalhos de Mendonça e Dubreuil (2005), Young (2005), Dumke (2007) e Lemos (2011), por meio de técnicas de sensoriamento remoto termal, para o aglomerado urbano da região metropolitana, e, em trabalhos de Rossi (2004) e Blanchet (2004), com coleta de dados meteorológicos em partes da cidade.

Conforme Mendonça e Dubreuil (2005), na cidade de Curitiba destaca-se a diferenciação de paisagens intraurbanas, que reflete a diversidade da organização do espaço e do uso do solo local-regional que, uma vez associados ao processo radiativo, evidenciam a formação de ilhas de calor alternadas com ilhas de frescor, embora se destaque como uma mancha mais quente e homogênea do que a área rural circunvizinha.

A cidade de Curitiba tem aspectos interessantes e características bem definidas para estudos de clima urbano, em virtude dos diferentes usos do solo, ordenados pelo zoneamento, que estabelece parâmetros de ocupação, e pela quantidade de diferentes tipos de florestas urbanas com distribuição irregular em sua área.

Segundo Schmitz e Mendonça (2011), a configuração espacial da cidade é marcada por uma maciça verticalização ao longo dos eixos estruturais, que transformou de forma radical o sistema urbano pré-existente, causando um importante impacto ambiental na paisagem urbana, no clima urbano e nos aspectos de conforto térmico. Para Danni-Oliveira (2000), ao longo dos eixos estruturais, criados para direcionar o crescimento da cidade e o fluxo de veículos, o zoneamento proporcionou a construção de altos edifícios, que formam cânions urbanos, alterando os campos térmicos, a iluminação natural, a ventilação e a qualidade do ar.

Vieira e Biondi (2008) verificaram que a cobertura vegetal diminuiu de $39 \%$ para $30 \%$ no território do município de Curitiba, de 1986 a 2004, como resultado do processo de crescimento urbano. $\mathrm{O}$ crescimento urbano se expandiu para além das áreas tradicionalmente mais densas, acentuando-se nas áreas contíguas a elas, numa resposta à saturação dessas áreas, ocasionando nesses locais uma grande diminuição da cobertura vegetal. 
Considerando que a distribuição e o arranjo das florestas urbanas influenciam de maneira distinta o clima dos diferentes setores de Curitiba e que os estudos realizados na cidade mostram genericamente o papel da vegetação sobre o clima local, este trabalho teve como objetivo analisar o efeito dos fatores zoneamento do uso do solo e vegetação na variação temporal e espacial da temperatura do ar nessa cidade.

\section{MATERIAL E MÉTODOS}

\section{Área de estudo}

O município de Curitiba, capital do estado do Paraná, localizado na região Sul do Brasil e fundado no ano de 1693 , ocupa o espaço geográfico de $432,17 \mathrm{~km}^{2}$ de área, na latitude $25^{\circ} 25^{\prime} 40^{\prime \prime} \mathrm{S}$ e longitude $49^{\circ} 16^{\prime} 23^{\prime \prime} \mathrm{W}$ (Marco Zero da Praça Tiradentes). A extensão do município é de $20 \mathrm{~km}$ de leste a oeste, dos bairros Orleans e Riviera ao bairro Cajuru, e de $35 \mathrm{~km}$ de norte a sul, dos bairros Abranches e Cachoeira ao bairro Caximba.

O clima de Curitiba apresenta médias térmicas que variam de $12,9{ }^{\circ} \mathrm{C}$, no mês mais frio, a $22,5^{\circ} \mathrm{C}$, no mês mais quente, com médias anuais de temperatura de $16,4^{\circ} \mathrm{C}$ e precipitação de $1600 \mathrm{~mm}$. Embora considerada de verão tipicamente fresco, a tropicalidade climática de Curitiba é evidenciada em momentos precisos, tais como a elevação das temperaturas entre novembro e março, com médias próximas de $20^{\circ} \mathrm{C}$. No inverno, as temperaturas são bastante baixas para os padrões tropicais do Brasil. Junho e julho são os meses mais frios do ano, nos quais a temperatura média pode chegar a $13{ }^{\circ} \mathrm{C}$ (MENDONÇA; DANNI-OLIVEIRA, 2007).

A cobertura vegetal dessa cidade, em 2004, foi estimada por Vieira e Biondi (2008) em 129.945.000 $\mathrm{m}^{2}$ ou $30 \%$ do seu território. A Prefeitura Municipal de Curitiba (2011), em levantamento realizado no ano de 2010, divulgou o total de 113 milhões $\mathrm{m}^{2}$ de áreas verdes, com índice de $64,5 \mathrm{~m}^{2} /$ habitante. Atualmente são consideradas florestas urbanas do município de Curitiba as seguintes tipologias: 22 parques, 16 bosques, 454 praças, 451 jardinetes, 55 largos, 16 eixos de animação, 31 núcleos ambientais, três jardins ambientais e quatro reservas particulares do patrimônio natural municipal. Estas, somadas, possuem uma área de 23.614.533 $\mathrm{m}^{2}$ (INSTITUTO DE PESQUISA E PLANEJAMENTO URBANO DE CURITIBA (IPPUC), 2012). Vieira e Biondi (2008) citam, no entanto, que as florestas urbanas são distribuídas irregularmente pelo município, com concentração da maioria dos parques e bosques na porção norte.

As disposições urbanísticas de Ocupação e Uso do Solo são regidas pelo zoneamento em vigor, as quais foram fixadas pela Lei Municipal $n^{\circ} 9.800 / 2000$ e decretos complementares, com configuração que inclui Zona Central, Zonas Residenciais, Zonas de Serviço, Zonas Industriais, Setores de Interesse Socioeconômico e Setores Especiais de Interesse Ambiental, entre outros (IPPUC, 2012).

\section{Procedimentos metodológicos}

A escala horizontal de análise considerada foi o clima local, que, conforme Andrade (2005), designa o clima das áreas homogêneas quanto à ocupação do solo ou condições topográficas, cuja dimensão pode variar de algumas dezenas a centenas de metros. Segundo World Meteorological Organization (2008), em áreas urbanas significa o clima de bairros com tipo similar de desenvolvimento.

A escala vertical se refere à urban canopy layer (camada urbana ao nível das coberturas), que compreende o espaço entre o solo e o nível médio das coberturas das edificações e representa a interação entre a atmosfera e os elementos urbanos (OKE, 1976).

A vegetação foi analisada de acordo com o conceito de florestas urbanas (MILLER, 1997; GONÇALVES; PAIVA, 2006), considerando os vários espaços que podem ser ocupados por um aglomerado de indivíduos arbóreos na área urbana.

Para a coleta de dados da temperatura do ar foram estabelecidos 44 pontos de monitoramento com instalação de miniabrigos meteorológicos em locais fixos em quatro transectos na malha urbana, cruzando um ponto central na Praça Tiradentes (marco zero da cidade) e estabelecendo-se 15 pontos no transecto norte-sul, 10 pontos no transecto leste-oeste, 12 pontos no transecto sudoeste-nordeste e 10 pontos no transecto noroeste-sudeste.

$\mathrm{Na}$ escolha dos locais de instalação dos miniabrigos meteorológicos, foram considerados os critérios de padronização, fácil acesso e segurança durante os períodos de coleta de dados. Os miniabrigos 
foram instalados ao longo das ruas no topo das hastes dos sinaleiros e placas de sinalização (semipórticos), o que atenderia aos critérios elencados, com a autorização da Urbanização de Curitiba S.A. (URBS) para uso das estruturas urbanas de responsabilidade desse órgão.

Os locais dos pontos de monitoramento, inicialmente distribuídos em um mapa, nos cruzamentos entre ruas, foram definidos em campo de acordo com a presença de sinaleiros e placas de sinalização. Na escolha dos pontos, evitaram-se estruturas muito próximas a árvores ou obstruções de construções, como prédios e paredes. Os pontos estabelecidos são apresentados na tabela 1 e figura 1.

Tabela 1. Localização dos pontos de monitoramento na cidade de Curitiba e respectiva classe de zoneamento do uso do solo.

Table 1. Location of monitoring points in the city of Curitiba and respective class of land use zoning.

\begin{tabular}{|c|c|c|c|c|c|}
\hline $\mathbf{N}^{\circ}$ & Localização & ZON & $\mathbf{N}^{\circ}$ & Localização & ZON \\
\hline P1 & Praça Tiradentes (Centro) & $\mathrm{SH}$ & $\mathrm{P} 23$ & $\begin{array}{l}\text { R. Dep. Néo Martins c/ R. Benjamin } \\
\text { Antonio Ansai (Fanny) }\end{array}$ & $\begin{array}{c}\text { SE-BR116 } \\
\text { ZR-3 }\end{array}$ \\
\hline P2 & $\begin{array}{l}\text { R. Visconde de Nácar c/ R. Emiliano } \\
\text { Perneta (Centro) }\end{array}$ & $\mathrm{ZC}$ & P24 & $\begin{array}{l}\text { R. Francisco Derosso c/ R. Cel. Luiz } \\
\text { José dos Santos (Xaxim) }\end{array}$ & ZR-2 \\
\hline P3 & $\begin{array}{l}\text { R. André de Barros c/ R. Barão do Rio } \\
\text { Branco (Centro) }\end{array}$ & $\mathrm{ZC}$ & P25 & $\begin{array}{l}\text { R. Odemir Silveira c/ R. Omar } \\
\text { Raymundo Picheth (Xaxim) }\end{array}$ & ZR-2 \\
\hline P4 & $\begin{array}{l}\text { R. Luiz Leão c/ R. Conselheiro Araújo } \\
\text { (Centro) }\end{array}$ & $\begin{array}{l}\text { ZR-4 } \\
\text { ZC }\end{array}$ & P26 & $\begin{array}{l}\text { R. Isaac Ferreira da Cruz c/ R. Levy } \\
\text { Buqueira (Sítio Cercado) }\end{array}$ & SE-LE \\
\hline P5 & $\begin{array}{l}\text { R. Inácio Lustosa c/ R. João Manoel (São } \\
\text { Francisco) }\end{array}$ & $\begin{array}{l}\text { ZR-4 } \\
\text { ZR-3 }\end{array}$ & P27 & $\begin{array}{l}\text { R. Tijucas do Sul n } 1859 \text { (Sítio } \\
\text { Cercado) }\end{array}$ & SEHIS \\
\hline P6 & $\begin{array}{l}\text { Av. Ver. Toaldo Túlio c/ Av. Três Marias } \\
\text { (São Braz) }\end{array}$ & $\begin{array}{l}\text { ZR-PC } \\
\text { ZR-2 }\end{array}$ & $\mathrm{P} 28$ & R. Nicola Pelanda n ${ }^{\circ} 4921$ (Umbará) & ZR-OC \\
\hline P7 & $\begin{array}{l}\text { R. Prof. Pedro Viriato Parigot de Souza c/ } \\
\text { R. Rosa Kaint Nadolny (Santo Inácio) }\end{array}$ & $\begin{array}{l}\text { SE-NC } \\
\text { ZT-NC }\end{array}$ & P29 & $\begin{array}{l}\text { R. Fredolin Wolf c/ R. Saturnino de } \\
\text { Miranda (Lamenha Pequena) }\end{array}$ & $\begin{array}{l}\text { ZR-2 } \\
\text { ZR-3 } \\
\end{array}$ \\
\hline P8 & $\begin{array}{l}\text { R. Cândido Hartmann c/ R. Padre } \\
\text { Ladislau Kula (Santo Inácio) }\end{array}$ & $\begin{array}{l}\text { ZR-1 } \\
\text { ZR-2 } \\
\end{array}$ & P30 & R. José Valle nº 1180 (São João) & ZR-SF \\
\hline P9 & $\begin{array}{l}\text { R. Euclides da Cunha c/ R. Padre } \\
\text { Agostinho (Bigorrilho) }\end{array}$ & $\begin{array}{c}\text { ZR-3 } \\
\text { SE }\end{array}$ & P31 & $\begin{array}{l}\text { R. Jacarezinho c/ R. Solimões (Vista } \\
\text { Alegre) }\end{array}$ & ZR-2 \\
\hline P10 & $\begin{array}{l}\text { R. Fernando Moreira c/ R. Desembargador } \\
\text { Motta (Mercês) }\end{array}$ & ZR-4 & P32 & $\begin{array}{l}\text { R. Guabirotuba c/ R. Imaculada } \\
\text { Conceição (Prado Velho) }\end{array}$ & $\begin{array}{l}\text { ZR-3 } \\
\text { SE-E }\end{array}$ \\
\hline P11 & $\begin{array}{l}\text { R. Ubaldino do Amaral c/ R. Visconde de } \\
\text { Guarapuava (Alto da Rua XV) }\end{array}$ & $\begin{array}{l}\text { ZR-4 } \\
\text { SE }\end{array}$ & P33 & $\begin{array}{l}\text { Av. Comendador Franco c/ R. Santo } \\
\text { Inácio de Loyola (Guabirotuba) }\end{array}$ & $\begin{array}{l}\text { SE-CF } \\
\text { ZR-2 }\end{array}$ \\
\hline P12 & $\begin{array}{l}\text { Av. Mal. Humberto de A. C. Branco c/ R. } \\
\text { Vitor Ferreira do Amaral (Cristo Rei) }\end{array}$ & $\begin{array}{l}\text { ZR-3 } \\
\text { ZR-1 }\end{array}$ & P34 & $\begin{array}{l}\text { Av. Salgado Filho c/ R. João Antonio } \\
\text { Prosdócimo (Jardim das Américas) }\end{array}$ & $\begin{array}{l}\text { SE-CF } \\
\text { ZR-3 }\end{array}$ \\
\hline P13 & $\begin{array}{l}\text { R. Vitor Ferreira do Amaral c/ Linha } \\
\text { Verde (Tarumã) }\end{array}$ & $\begin{array}{l}\text { SE-BR116 } \\
\text { ZR-3 }\end{array}$ & P35 & $\begin{array}{l}\text { R. Velci Bolívar Grando c/ R. Amauri } \\
\text { Mauad Guérios (Uberaba) }\end{array}$ & SEHIS \\
\hline P14 & $\begin{array}{l}\text { R. Vitor Ferreira do Amaral c/ R. Brasílio } \\
\text { de Lara (Capão da Imbuia) }\end{array}$ & $\begin{array}{c}\text { ZR-2 } \\
\text { SEHIS }\end{array}$ & P36 & $\begin{array}{l}\text { R. Raul Pompeia c/ R. Ludovico } \\
\text { Kaminski (CIC) }\end{array}$ & SEHIS \\
\hline P15 & $\begin{array}{l}\text { Av. Anita Garibaldi c/ R. Rolando Salin } \\
\text { Zappa Mansur (Cachoeira) }\end{array}$ & $\begin{array}{c}\text { ZR-2 } \\
\text { ZR-OC } \\
\end{array}$ & P37 & $\begin{array}{l}\text { R. Raul Pompeia c/ R. João Dembinski } \\
\text { (Fazendinha) }\end{array}$ & $\begin{array}{l}\text { ZUM } \\
\text { ZR-2 } \\
\end{array}$ \\
\hline P16 & $\begin{array}{l}\text { Av. Anita Garibaldi c/ R. Flávio } \\
\text { Dallegrave (Barreirinha) }\end{array}$ & ZR-2 & P38 & R. Carlos Klemtz n 310 (Portão) & $\begin{array}{c}\text { CONEC-3 } \\
\text { ZR-2 } \\
\end{array}$ \\
\hline P17 & $\begin{array}{l}\text { R. João Gava c/ R. Antonio Krainiski } \\
\text { (Abranches) }\end{array}$ & ZR-2 & P39 & $\begin{array}{l}\text { R. Curupaitis c/ R. Ulisses Vieira } \\
\text { (Santa Quitéria) }\end{array}$ & ZR-3 \\
\hline P18 & R. Mateus Leme nº 3238 (São Lourenço) & ZR-2 & P40 & $\begin{array}{l}\text { Av. Sete de Setembro c/ R. Castro } \\
\text { Alves (Batel) }\end{array}$ & $\begin{array}{c}\text { ZR-4 } \\
\text { SE }\end{array}$ \\
\hline P19 & $\begin{array}{l}\text { R. Dep. Mário de Barros c/ R. Raul Viana } \\
\text { (Centro Cívico) }\end{array}$ & ZE-CC & P41 & $\begin{array}{l}\text { R. Jaime Balão c/ R. Nossa Senhora da } \\
\text { Luz (Hugo Lange) }\end{array}$ & $\begin{array}{l}\text { ZR-3 } \\
\text { ZR-1 }\end{array}$ \\
\hline P20 & $\begin{array}{l}\text { R. Brasílio Itiberê c/ R. Brigadeiro Franco } \\
\text { (Rebouças) }\end{array}$ & $\begin{array}{l}\text { ZR-4 } \\
\text { ZR-3 }\end{array}$ & P42 & $\begin{array}{l}\text { Av. Prefeito Erasto Gaertner c/ R. } \\
\text { Marcelino Nogueira (Bacacheri) }\end{array}$ & $\begin{array}{l}\text { ZR-4 } \\
\text { ZE-M }\end{array}$ \\
\hline P21 & $\begin{array}{l}\text { Av. Presidente Kennedy c/ R. Minas } \\
\text { Gerais (Guaíra) }\end{array}$ & ZR-3 & P43 & $\begin{array}{l}\text { Av. Monteiro Tourinho c/ R. Max } \\
\text { Rosenmann (Tingui) }\end{array}$ & $\begin{array}{l}\text { ZR-4 } \\
\text { ZR-3 }\end{array}$ \\
\hline $\mathrm{P} 22$ & $\begin{array}{l}\text { R. Wenceslau Braz c/ R. Camilo Castelo } \\
\text { Branco (Lindoia) }\end{array}$ & SE-WB & P44 & $\begin{array}{l}\text { R. Estrada das Olarias c/ R. Arnaldo W. } \\
\text { Gaensli (Santa Cândida) }\end{array}$ & ZR-2 \\
\hline
\end{tabular}

ZON: classe de zoneamento do uso do solo; SH: Setor Especial Histórico; ZC: Zona Central; ZR-4: Zonas Residenciais de médiaalta densidade; ZR-3: Zonas Residenciais de média densidade; ZR-PC: Zonas Residenciais com baixa densidade; ZR-2: Zonas Residenciais com baixa densidade; SE-NC: Setor Especial da Nova Curitiba; ZT-NC: Zona de Transição do Setor Especial Nova Curitiba; ZR-1: Zonas Residenciais com baixíssima densidade; SE: Setor Especial Estrutural; SE-BR116: Setor Especial da BR-116; SEHIS: Setor Especial de Habitação de Interesse Social; ZR-OC: Zona Residencial de Ocupação Controlada; SE-CC: Setor Especial Centro Cívico; SE-WB: Setor Especial Av. Presidente Wenceslau Braz; SE-LE: Setor Especial Linhão do Emprego; ZR-SF: Zona Residencial de Santa Felicidade; ZUM: Zonas de Uso Misto; CONEC: Setor Especial Conectoras; ZE-M: Zona Especial Militar. 


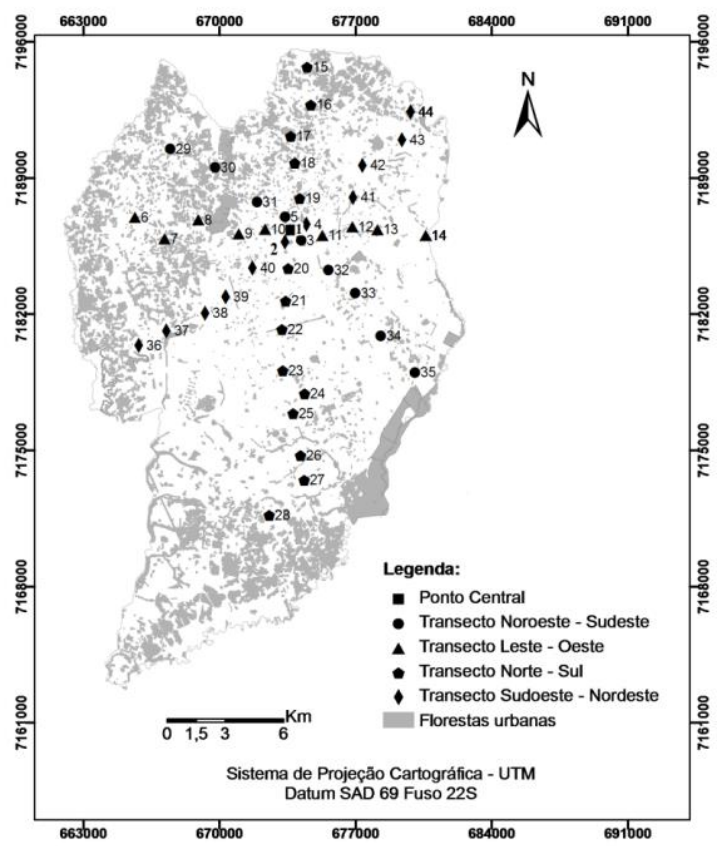

Figura 1. Localização dos pontos de monitoramento na cidade de Curitiba.

Figure 1. Location of monitoring points in the city of Curitiba.

Os equipamentos foram instalados nas hastes dos sinaleiros ou placas de sinalização, a uma altura média de quatro metros do solo (Figura 2A). Segundo World Meteorological Organization (2008), há flexibilidade para coletar dados meteorológicos em áreas urbanas em alturas maiores (3 a $5 \mathrm{~m}$ ) daquelas coletadas na altura padrão $(1,25$ a $2,00 \mathrm{~m})$, sem necessidade de correção de dados, tendo maior cobertura "footprints" e localizando o sensor em área de difícil alcance, prevenindo danos por vandalismo, além de assegurar maior diluição do calor de exaustão de veículos e reduzir a contaminação pela poeira.

Os dados de temperatura do ar foram coletados com registradores modelo Hobo®, marca Onset, previamente aferidos. Em campo, os registradores foram colocados em miniabrigos meteorológicos, ajustados ao tamanho do sensor, confeccionados com uma seção de tubo de PVC revestida externamente com papel alumínio (Figura 2B), descritos em Leal (2012).

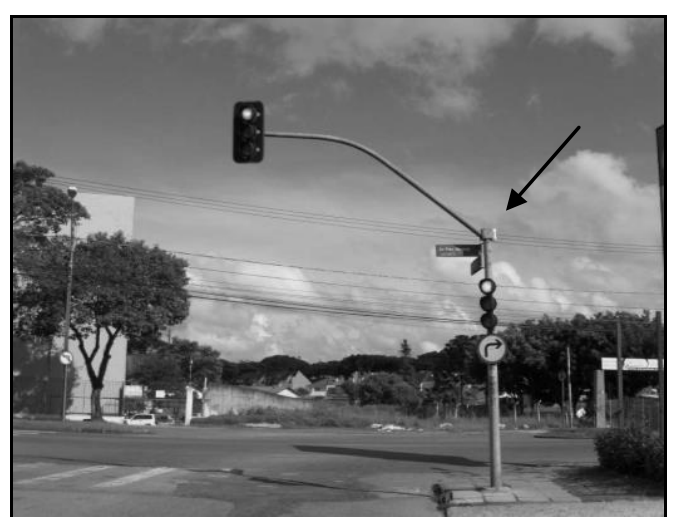

A

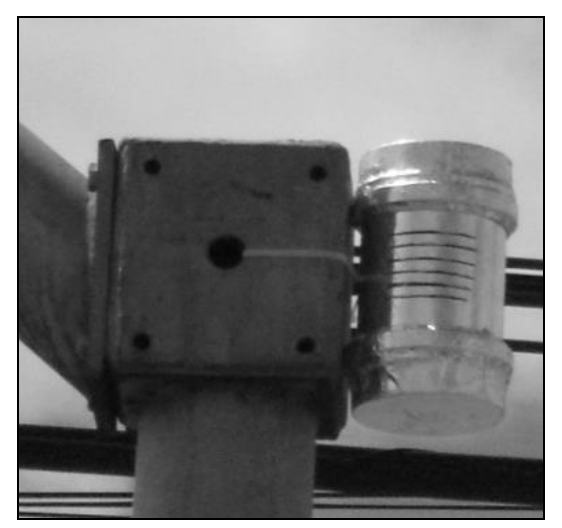

B

Figura 2. Exemplo de miniabrigo meteorológico instalado em sinaleiro (A) e detalhe (B).

Figure 2. Example of mini-shields installed on traffic light posts (A) and detail (B). 
A coleta de dados foi realizada em quatro campanhas, cada uma com duração de 22 dias, com coleta contínua de dados de 15 em 15 minutos ( $0 \mathrm{~h} 00$ às $23 \mathrm{~h} 45 \mathrm{~min}$ de cada dia), em períodos correspondentes às estações do ano em 2011: verão (07 a 28 de fevereiro), outono (09 a 30 de maio), inverno (04 a 25 de agosto) e primavera (03 a 24 de novembro).

Com os dados coletados foram calculadas a média geral do período (considerando todas as leituras do período monitorado em cada estação), a média das máximas e mínimas diárias de temperatura (do maior e do menor valor registrados em cada data de monitoramento), com desvio padrão, e as máximas e mínimas absolutas (maior e menor valor registrado no período observado).

Para essas variáveis, separadamente para cada transecto, foram obtidas as diferenças térmicas entre os pontos de monitoramento. As diferenças térmicas encontradas foram consideradas representativas quando maiores que $0,5^{\circ} \mathrm{C}$, seguindo o mesmo critério de Yow e Carbone (2006).

Os resultados foram comparados com as características do zoneamento do uso do solo e florestas urbanas, segundo dados do Instituto de Pesquisa e Planejamento Urbano de Curitiba (IPPUC, 2012).

\section{RESULTADOS E DISCUSSÃO}

\section{Variação térmica no transecto norte-sul}

No transecto norte-sul, em todas as estações do ano, foram encontradas diferenças térmicas entre os pontos de monitoramento (Tabela 2). Os resultados demonstram a variação térmica da cidade de Curitiba, corroborando os trabalhos de Blanchet (2004), Rossi (2004), Mendonça e Dubreuil (2005), Young (2005), Dumke (2007) e Lemos (2011).

As maiores diferenças térmicas entre os pontos de monitoramento foram de $1,7{ }^{\circ} \mathrm{C}$ para temperatura média no período correspondente ao outono, $3,3{ }^{\circ} \mathrm{C}$ para temperatura máxima no verão e primavera e $4,2^{\circ} \mathrm{C}$ para temperatura mínima absoluta no outono (Tabela 2).

As maiores temperaturas médias foram encontradas no ponto P1 (Praça Tiradentes - Centro), na área central consolidada (Zona Central - ZC) e que foi definido como ponto central dos transectos, e nos pontos P18 (R. Mateus Leme - São Lourenço), em Zona Residencial de Baixa Densidade (ZR-2), P20 (R. Brasílio Itiberê com R. Brigadeiro Franco - Bairro Rebouças), entre Zonas Residenciais de MédiaAlta Densidade (ZR-4) e de Média Densidade (ZR-3), e P21 (Av. Presidente Kennedy com R. Minas Gerais - Guaíra), em Zona Residencial de Média Densidade (ZR-3). Esses pontos de monitoramento localizam-se todos em áreas bastante urbanizadas e com alto fluxo de veículos, com tipologias de florestas urbanas limitadas às praças, jardinetes e arborização de ruas.

Nos pontos P1, P20 e P21, de maior adensamento urbano, ocorreram as maiores temperaturas mínimas absolutas e média das mínimas diárias de temperatura, o que demonstra o efeito de aquecimento provocado pela urbanização.

As maiores temperaturas máximas absolutas, que evidenciam as maiores diferenças entre os ambientes nos períodos de máximo aquecimento, foram encontradas nos pontos P20 e P21, no verão, estação do ano que apresenta os maiores valores de temperatura, e nos pontos P24 (R. Francisco Derosso com R. Cel. Luiz José dos Santos - Xaxim) e P16 (Av. Anita Garibaldi com R. Rolando Salin Zappa Mansur - bairro Cachoeira), em Zona Residencial de Baixa Densidade (ZR-2), na primavera. Para a variável média das máximas diárias destacou-se também pelas maiores temperaturas o ponto P25 (R. Odemir Silveira com R. Omar Raymundo Picheth - Xaxim), em ZR-2, localizado ao sul da cidade.

O bairro Xaxim, onde estão localizados os pontos P24 e P25 é o sexto bairro mais populoso da cidade de Curitiba, segundo o último censo demográfico realizado (IPPUC, 2012). Os bairros mais populosos de Curitiba estão localizados na região sul e leste, que não são os de maior densidade de construção pelo zoneamento do uso do solo. Na região há loteamentos, com tamanho de lote reduzido, aliado à menor presença de vegetação natural e implantada. Isso resulta em alterações no clima local, com temperaturas semelhantes à da área central.

Os menores valores das variáveis de temperatura analisadas ocorreram nos pontos P15 (Av. Anita Garibaldi com R. Flávio Dallegrave - Bairro Barreirinha), P16 (Av. Anita Garibaldi com R. Rolando Salin Zappa Mansur - Bairro Cachoeira), P27 (R. Tijucas do Sul n ${ }^{\circ} 1859$ - Sítio Cercado) e P28 (R. Nicola Pelanda ${ }^{\circ} 4921$ - Umbará), em ambos os extremos do transecto. Os pontos P15 e P28, próximos aos limites do município, estão localizados em Zona Residencial de Ocupação Controlada (ZROC), o ponto P16 em Zona Residencial de Baixa Densidade (ZR-2) e o ponto P27 em Setor Especial de Habitação de Interesse Social (SEHIS), com taxa de ocupação até 30\%. Nesses locais há grande concentração de florestas urbanas. O ponto P15 está próximo do Parque Municipal Nascentes do Belém e 
entre os pontos P15 e P16 encontra-se o Parque Municipal da Barreirinha. O ponto P27 está localizado próximo a um canteiro central gramado referente à faixa de servidão de linha de transmissão de energia. A baixa densidade de construção e a presença das florestas urbanas explicam as menores temperaturas encontradas nesses pontos.

Tabela 2. Temperaturas observadas no transecto norte-sul na cidade de Curitiba nos períodos correspondentes as estações do ano de 2011.

Table 2. Temperatures observed in the north-south transect in the city of Curitiba, corresponding to the seasons of 2011.

\begin{tabular}{|c|c|c|c|c|c|c|c|c|c|c|c|c|c|c|c|c|}
\hline & \multicolumn{15}{|c|}{ Pontos de monitoramento } & \\
\hline & P15 & P16 & P17 & P18 & P19 & P1 & $\mathbf{P 2 0}$ & $\mathbf{P 2 1}$ & $\mathbf{P 2 2}$ & $\mathbf{P 2 3}$ & P24 & P25 & P26 & P27 & $\mathbf{P 2 8}$ & \\
\hline \multicolumn{17}{|c|}{ Temperatura média $\left({ }^{\circ} \mathrm{C}\right)$} \\
\hline \multirow[b]{2}{*}{ V } & 20,8 & 21,4 & 21,2 & 22,0 & 21,6 & 21,9 & 22,0 & 22,0 & 21,5 & 21,3 & 21,6 & 21,7 & 21,8 & 21,0 & 21,0 & \\
\hline & $\pm 3,8$ & $\pm 3,7$ & $\pm 3,6$ & $\pm 3,8$ & $\pm 3,6$ & $\pm 3,5$ & $\pm 3,7$ & $\pm 3,6$ & \pm 3 & $\pm 3,6$ & $\pm 3,9$ & $\pm 3,7$ & $\pm 3,7$ & $\pm 3,1$ & $\pm 3,6$ & \\
\hline \multirow{2}{*}{$\mathrm{O}$} & 14,6 & 13,9 & 14,2 & 14,9 & 14,5 & 15,3 & 15,6 & & & & 14,9 & 15,0 & 15,0 & 14,7 & 14,2 & \\
\hline & $\pm 4,3$ & $\pm 4,3$ & $\pm 4,1$ & $\pm 4,2$ & $\pm 4,0$ & $\pm 3,8$ & $\pm 4,3$ & & $\pm 4,2$ & $\pm 4,1$ & $\pm 4,3$ & $\pm 4,2$ & $\pm 4,0$ & $\pm 4,1$ & $\pm 4,1$ & \\
\hline \multirow{3}{*}{ I } & 14,0 & 14,5 & 14,1 & 14,6 & 14,5 & 15,0 & 15,2 & & 14,6 & 14,3 & 14,6 & 14,6 & 14,6 & 14,3 & 14,0 & \\
\hline & $\pm 5,8$ & $\pm 5,8$ & $\pm 5,8$ & $\pm 5,8$ & $\pm 5,8$ & $\pm 5,5$ & \pm 5 & & $\pm 5,7$ & $\pm 5,7$ & $\pm 5,8$ & $\pm 5,8$ & $\pm 5,7$ & $\pm 5,6$ & $\pm 5,7$ & \\
\hline & 16,8 & 17,9 & 17,4 & 18,3 & 17,9 & 18,3 & 18, & & & 17,5 & 18,0 & 18,2 & 18,1 & 17,5 & 17,3 & \\
\hline \multirow{2}{*}{$\mathrm{P}$} & $\pm 5,0$ & $\pm 5,1$ & $\pm 4,9$ & $\pm 5,1$ & $\pm 4,9$ & $\pm 4,9$ & $\pm 5,1$ & $\pm 5,0$ & $\pm 4,7$ & $\pm 4,8$ & $\pm 5,2$ & $\pm 5,1$ & $\pm 5,0$ & $\pm 4,7$ & $\pm 5,1$ & \\
\hline & \multicolumn{16}{|c|}{ Temperatura máxima absoluta $\left({ }^{\circ} \mathrm{C}\right)$} \\
\hline $\mathrm{V}$ & 33,2 & 31,9 & 32,8 & 32,3 & 33,6 & 33,2 & 34,4 & 34,4 & 32,3 & 32,8 & 33,6 & 34,0 & 32,8 & 31,1 & 34,0 & 3,3 \\
\hline $\mathrm{O}$ & 26,3 & 26,3 & 25,6 & 26,0 & 25,2 & 25,2 & & & & & 26,3 & 27,1 & 26,0 & 26,0 & 26,3 & 2,7 \\
\hline I & 29,5 & 29,5 & 30,3 & 30,7 & 29,9 & 29,9 & 30 & 30 & 30 & 29,9 & 30,7 & 29,5 & 30,3 & 29,5 & 29,5 & 1,2 \\
\hline $\mathrm{P}$ & 31,1 & 34,0 & 31,9 & 32,3 & 32,3 & 32,8 & 32,8 & 32,8 & 31,1 & 31,5 & 34,0 & 32,8 & 33,6 & 30,7 & 32,3 & 3,3 \\
\hline \multicolumn{17}{|c|}{ Temperatura mínima absoluta $\left({ }^{\circ} \mathrm{C}\right)$} \\
\hline $\mathrm{V}$ & 15,2 & 15,6 & 15,2 & 15,6 & 15,6 & 16,4 & 16,0 & 16,0 & 15,6 & 15,2 & 15,2 & 15,6 & 15,6 & 15,2 & 14,9 & 1,5 \\
\hline $\mathrm{O}$ & 3,7 & 2,5 & 3,3 & 3,7 & 3,7 & 6,6 & 6 & & & & 5,4 & 5,0 & 5,8 & 5,0 & 3,7 & 4,2 \\
\hline I & 1,2 & 2,0 & 0,3 & 0,3 & 0,7 & 3,3 & 2 & 1 & 1,6 & 1 , & 1,2 & 0,3 & 1,2 & 1,2 & 0,7 & 3,0 \\
\hline $\mathrm{P}$ & 7,8 & 8,2 & 7,8 & 8,6 & 8,2 & 9,0 & 9,8 & 9,0 & 9,4 & 9,0 & 8,6 & 8,6 & 8,6 & 8,6 & 7,8 & 2,0 \\
\hline \multicolumn{17}{|c|}{ Média das máximas diárias de temperatura $\left({ }^{\circ} \mathrm{C}\right)$} \\
\hline \multirow{3}{*}{$\mathrm{V}$} & 28,2 & 28,2 & 27,8 & 28,7 & 28,3 & 28,5 & 28,6 & 28,5 & 27,7 & 27,9 & 28,4 & 28,8 & & 26,2 & 27,7 & \\
\hline & $\pm 3,9$ & $\pm 3,6$ & $\pm 3,5$ & $\pm 3,5$ & $\pm 3,7$ & $\pm 3,1$ & \pm & \pm & \pm 3 , & & $\pm 3,9$ & $\pm 3,9$ & 3,8 & $\pm 3,4$ & $\pm 4,1$ & \\
\hline & 19,6 & 18,9 & 18,4 & 19,6 & 18 & 19,4 & & & & & 19 & 19,6 & & 19,5 & 8,8 & \\
\hline \multirow{2}{*}{$\mathrm{O}$} & $\pm 5,5$ & $\pm 5,6$ & $\pm 5,1$ & $\pm 5,2$ & $\pm 5,0$ & $\pm 4,6$ & \pm 5 & \pm 5 & \pm 5 & \pm & $\pm 5,4$ & $\begin{array}{l} \pm 5,3 \\
\end{array}$ & $\pm 5,1$ & $\pm 5,3$ & $\begin{array}{l} \pm 5,4 \\
\end{array}$ & \\
\hline & 20,5 & 20,8 & 20,8 & 21,3 & 20,9 & 20,8 & 21,2 & 20,9 & 21,2 & 20,4 & 21,3 & 20,8 & 20,7 & 20,4 & 0,4 & \\
\hline \multirow{2}{*}{ I } & & & & & & $\pm 6,3$ & & & & & $\pm 6,6$ & $\pm 6,5$ & & $\pm 6,5$ & & \\
\hline & 23,7 & 24,4 & 23,3 & 24,7 & 23,9 & 24,9 & 24,8 & 24 & 23 & 23,7 & 21,2 & 24,9 & 24,7 & 23,5 & 24,0 & \\
\hline$P$ & $\pm 5,2$ & $\pm 5,5$ & $\pm 5,2$ & $\pm 5,0$ & $\pm 5,1$ & $\pm 5,0$ & $\pm 5,2$ & $\pm 5,3$ & $\pm 5,0$ & $\pm 5,1$ & $\pm 5,3$ & & & $\pm 4,8$ & & \\
\hline \multicolumn{17}{|c|}{ Média das mínimas diárias de temperatura $\left({ }^{\circ} \mathrm{C}\right)$} \\
\hline \multirow{3}{*}{$\mathrm{V}$} & 15,2 & 15,6 & 15,2 & 15,6 & 15,6 & 16,4 & & 16,0 & 15 & & 15,2 & 15,6 & & 15,2 & 14,9 & \\
\hline & & $\pm 1,9$ & & \pm 1 & & $\pm 1,8$ & \pm 1 & \pm 1 & \pm 1 & & \pm 1 & $\pm 1,7$ & & $\pm 1,6$ & ,7 & \\
\hline & 10,7 & 10,0 & 10,4 & 11,1 & 10 , & 12,1 & 11 & 11 & 11 & 11 & 11 & 11,3 & & 11,1 & 10,7 & \\
\hline \multirow{2}{*}{$\mathrm{O}$} & $\pm 3,3$ & $\pm 3,4$ & $\pm 3,3$ & $\pm 3,0$ & $\pm 3,1$ & $\pm 2,8$ & \pm 2 & \pm 3 & \pm 2 & \pm 2 & $\pm 2,9$ & $\pm 2,9$ & & $\pm 2,8$ & $\pm 2,8$ & 2,1 \\
\hline & 9,5 & 9,8 & 9,4 & 9,8 & 9, & 10,7 & 10 & 10,0 & 10,0 & 9,7 & 9 , & 9,8 & 10 & 9,7 & 9,3 & \\
\hline I & $\pm 4,0$ & $\pm 3,8$ & & $\pm 3,8$ & & $\pm 3,8$ & $\pm 3,7$ & & & & $\pm 3,9$ & $\pm 3,9$ & & $\pm 3,9$ & $\pm 3,9$ & \\
\hline \multirow{2}{*}{$P$} & 12,0 & 12,7 & 12,5 & 13,3 & 13,0 & 13,6 & 13,6 & 13,5 & 13,2 & 12,9 & 13,0 & 13,2 & 13,4 & 13,1 & 12,5 & \\
\hline & $\pm 2,6$ & $\pm 2,6$ & $\pm 2,6$ & $\pm 2,6$ & $\pm 2,6$ & $\pm 2,6$ & $\pm 2,6$ & $\pm 2,6$ & $\pm 2,4$ & $\pm 2,4$ & $\pm 2,5$ & $\pm 2,5$ & $\pm 2,5$ & $\pm 2,4$ & $\pm 2,6$ & \\
\hline
\end{tabular}

P: período; V: verão; O: outono; I: inverno; P: primavera; DT: diferença térmica.

\section{Variação térmica no transecto leste-oeste}

Comparando-se as temperaturas entre os pontos próximos das florestas urbanas, verificaram-se menores temperaturas nos pontos P17, P19 e P22, relacionadas ao efeito da vegetação. Os Parques São Lourenço, com área de $203.918 \mathrm{~m}^{2}$, e das Pedreiras (Ópera de Arame), com área de $103.500 \mathrm{~m}^{2}$, estão localizados próximos ao ponto P17, e o Bosque João Paulo II (Bosque do Papa), com área de $48.000 \mathrm{~m}^{2}$, nas proximidades do ponto P19. O ponto P22 localiza-se junto ao Eixo de Animação Arnaldo Faivro 
Busato), com área de $103.200 \mathrm{~m}^{2}$, apresentando canteiro gramado e arborização com espécie de grande porte, Tipuana tipu (Benth.) Kuntze (tipuana). Esses resultados evidenciam o efeito de resfriamento das florestas urbanas presentes na cidade de Curitiba.

No transecto leste-oeste, as maiores diferenças térmicas encontradas foram de $5{ }^{\circ} \mathrm{C}$ para a temperatura máxima absoluta nos períodos correspondentes ao verão e a primavera (Tabela 3). As maiores temperaturas máximas absolutas, bem como as temperaturas médias do ar e as médias das máximas diárias de temperatura ocorreram no ponto P13 (R. Vitor Ferreira do Amaral com Linha Verde Tarumã), que se refere a uma área de média densidade de construção (SE-BR 116 - Setor Especial da BR 116) com alta circulação de veículos e ainda próxima à Linha Verde, com tráfego pesado, demonstrando a adição de calor antropogênico pelo trânsito e a consequente variação térmica em área urbana.

Tabela 3. Temperaturas observadas no transecto leste-oeste na cidade de Curitiba nos períodos correspondentes às estações do ano de 2011.

Table 3. Temperature observed in the east-west transect in the city of Curitiba, corresponding to the seasons of 2011.

\begin{tabular}{|c|c|c|c|c|c|c|c|c|c|c|c|}
\hline \multirow{3}{*}{$\mathbf{P}$} & \multicolumn{10}{|c|}{ Pontos de monitoramento } & \\
\hline & P6 & P7 & P8 & P9 & P10 & P1 & P11 & P12 & P13 & P14 & \\
\hline & \multicolumn{11}{|c|}{ Temperatura média $\left({ }^{\circ} \mathrm{C}\right)$} \\
\hline $\mathrm{V}$ & $21,7 \pm 4,0$ & $21,4 \pm 3,9$ & $21,2 \pm 3,7$ & $21,7 \pm 3,5$ & $22,0 \pm 3,9$ & $21,9 \pm 3,5$ & $21,7 \pm 3,8$ & $21,5 \pm 3,6$ & $22,2 \pm 4,1$ & $21,9 \pm 3,8$ & 1,2 \\
\hline $\mathrm{O}$ & $14,7 \pm 4,1$ & $14,5 \pm 4,1$ & $14,2 \pm 3,9$ & $15,0 \pm 3,8$ & $15,1 \pm 4,1$ & $15,3 \pm 3,8$ & $15,0 \pm 4,2$ & $14,8 \pm 4,1$ & $15,3 \pm 4,4$ & $14,7 \pm 4,1$ & 1,5 \\
\hline I & $14,7 \pm 5,9$ & $14,6 \pm 6,0$ & $14,3 \pm 5,9$ & $14,8 \pm 5,6$ & $14,9 \pm 5,8$ & $15,0 \pm 5,5$ & $14,9 \pm 6,0$ & $14,7 \pm 5,9$ & $15,0 \pm 5,9$ & $14,6 \pm 5,7$ & 1,2 \\
\hline $\mathrm{P}$ & $17,9 \pm 5,0$ & $17,9 \pm 5,3$ & $17,2 \pm 4,6$ & $18,1 \pm 4,8$ & $18,2 \pm 5,1$ & $18,3 \pm 4,9$ & $17,7 \pm 4,8$ & $17,7 \pm 4,9$ & $18,6 \pm 5,4$ & $17,9 \pm 5,0$ & 1,5 \\
\hline \multicolumn{12}{|c|}{ Temperatura máxima absoluta $\left({ }^{\circ} \mathrm{C}\right)$} \\
\hline V & 33,6 & 34,9 & 33,6 & 32,3 & 34,4 & 33,2 & 34,0 & 33,2 & 35,3 & 34,4 & 5,0 \\
\hline $\mathrm{O}$ & 25,6 & 25,2 & 24,4 & 25,2 & 26,3 & 25,2 & 27,9 & 27,5 & 27,9 & 25,6 & 3,5 \\
\hline I & 29,9 & 31,1 & 30,3 & 29,5 & 30,7 & 29,9 & 31,9 & 31,5 & 31,1 & 31,1 & 2,4 \\
\hline $\mathrm{P}$ & 31,5 & 34,9 & 29,9 & 32,8 & 33,2 & 32,8 & 31,9 & 32,8 & 34,4 & 32,8 & 5,0 \\
\hline \multicolumn{12}{|c|}{ Temperatura mínima absoluta $\left({ }^{\circ} \mathrm{C}\right)$} \\
\hline $\mathrm{V}$ & 15,6 & 15,2 & 15,6 & 16,4 & 16,0 & 16,4 & 16,0 & 16,0 & 16,0 & 16,0 & 1,2 \\
\hline $\mathrm{O}$ & 3,7 & 4,2 & 4,6 & 5,0 & 5,0 & 6,6 & 6,2 & 5,4 & 5,0 & 4,6 & 3,3 \\
\hline I & 2,0 & 1,6 & 0,7 & 2,5 & 2,5 & & 2, & 1, & 1,6 & 0,3 & 3,0 \\
\hline $\mathrm{P}$ & 9,0 & 8,6 & 8,6 & 9,8 & 9,0 & 9,0 & 9,4 & 8,6 & 9,0 & 9,0 & 1,6 \\
\hline \multicolumn{12}{|c|}{ Média das máximas diárias de temperatura $\left({ }^{\circ} \mathrm{C}\right)$} \\
\hline $\mathrm{V}$ & $29,5 \pm 3,9$ & $28,9 \pm 4,2$ & $28,4 \pm 4,1$ & $28,2 \pm 3,6$ & $29,5 \pm 4,0$ & $28,5 \pm 3,1$ & $28,4 \pm 3,9$ & $27,8 \pm 3,8$ & $29,5 \pm 4,2$ & $28,3 \pm 4,3$ & 2,7 \\
\hline $\mathrm{O}$ & $19,1 \pm 4,6$ & $19,0 \pm 5,6$ & $18,5 \pm 5,4$ & $18,9 \pm 5,4$ & $19,6 \pm 5,2$ & $19,4 \pm 5,0$ & $19,7 \pm 5,2$ & $19,2 \pm 5,0$ & $20,8 \pm 4,6$ & $19,4 \pm 5,1$ & 2,3 \\
\hline I & $20,6 \pm 6,5$ & $21,3 \pm 7,0$ & $21,0 \pm 6,7$ & $20,7 \pm 6,2$ & $21,2 \pm 6,6$ & $20,8 \pm 6,2$ & $21,5 \pm 7,2$ & $21,1 \pm 6,7$ & $22,3 \pm 6,8$ & $21,4 \pm 6,5$ & 1,7 \\
\hline $\mathrm{P}$ & $24,2 \pm 4,8$ & $25,3 \pm 6,1$ & $22,3 \pm 4,4$ & $24,3 \pm 5,2$ & $25,0 \pm 5,4$ & $24,9 \pm 5,0$ & $23,5 \pm 5,3$ & $23,6 \pm 5,4$ & $25,9 \pm 5,5$ & $24,0 \pm 5,5$ & 3,5 \\
\hline \multicolumn{12}{|c|}{ Média das mínimas diárias de temperatura $\left({ }^{\circ} \mathrm{C}\right)$} \\
\hline $\mathrm{V}$ & $17,8 \pm 1,2$ & $17,7 \pm 1,2$ & $17,7 \pm 1,1$ & $18,3 \pm 1,1$ & $18,2 \pm 1,2$ & $18,4 \pm 1,2$ & $18,1 \pm 1,3$ & $17,9 \pm 1,3$ & $18,1 \pm 1,3$ & $18,1 \pm 1,3$ & 1,1 \\
\hline $\mathrm{O}$ & $11,0 \pm 3,0$ & $10,9 \pm 3,0$ & $10,9 \pm 3,0$ & $11,7 \pm 2,8$ & $11,4 \pm 2,9$ & $12,1 \pm 2,8$ & $11,5 \pm 2,9$ & $11,2 \pm 3,0$ & $11,4 \pm 3,1$ & $11,0 \pm 3,0$ & 1,4 \\
\hline I & $10,1 \pm 4,1$ & $10,0 \pm 4,1$ & $9,7 \pm 4,1$ & $10,5 \pm 3,9$ & $10,3 \pm 3,9$ & $10,7 \pm 3,8$ & $10,2 \pm 3,8$ & $10,0 \pm 3,9$ & $10,1 \pm 3,7$ & $9,8 \pm 3,7$ & 1,2 \\
\hline $\mathrm{P}$ & $12,8 \pm 2,4$ & $12,8 \pm 2,5$ & $12,7 \pm 2,3$ & $13,6 \pm 2,4$ & $13,3 \pm 2,4$ & $13,6 \pm 2,6$ & $13,3 \pm 2,5$ & $13,0 \pm 2,5$ & $13,3 \pm 2,5$ & $13,1 \pm 2,5$ & 1,1 \\
\hline
\end{tabular}

Além do ponto P1 (Praça Tiradentes - Centro), já destacado no item anterior como entre os de maior temperatura média, os pontos P10 (R. Fernando Moreira c/ R. Desembargador Motta - Mercês) e P11 (R. Ubaldino do Amaral c/ R. Visconde de Guarapuava - Alto da Rua XV), localizados em Zona Residencial de Média-Alta Densidade (ZR-4), se destacaram pelas maiores temperaturas médias e também pelos maiores valores das temperaturas máximas e mínimas absolutas. No entanto o ponto P1 apresentou temperaturas máximas absolutas de 0,4 a $2,7^{\circ} \mathrm{C}$ menores do que as dos pontos adjacentes (P10 e P11), além de apresentar os maiores valores de temperatura mínima absoluta e média das mínimas diárias de temperatura (Tabela 3), o que demonstra menor amplitude térmica nessa área bastante urbanizada. 
Segundo Klysik e Fortuniak (1999), a área central, com maior densidade de construção, pode ser mais fria que os arredores durante o dia nos locais que estão à sombra. Dumke (2007) verificou que, de modo geral, em oito pontos na cidade de Curitiba, as temperaturas mais elevadas não ocorrem nas áreas mais verticalizadas do centro e dos setores estruturais, embora predominem temperaturas também altas nesses locais, o que pode ser explicado pelo sombreamento dos edifícios, impedindo a incidência da radiação solar direta sobre as superfícies. Mesmo assim as temperaturas são bastante elevadas nesses locais, devido à produção de calor urbano e à massa térmica das edificações.

Em todas as estações do ano, o ponto P8 (R. Cândido Hartmann com R. Padre Ladislau Kula Santo Inácio) apresentou os menores valores de temperatura média e média das mínimas diárias. A maior redução de temperatura nesse ponto, ao invés de ocorrer no extremo do transecto, é explicada pela presença de remanescentes florestais próximos, incluindo o Parque Municipal Barigui, grande área verde com $1.400 .000 \mathrm{~m}^{2}$, que inclui cobertura florestal e lago (IPPUC, 2012), fatores amenizadores climáticos. Outro aspecto analisado é a alteração da densidade de ocupação, que no ponto P8 é de baixíssima a baixa densidade (ZR-1 e ZR-2), enquanto nos pontos adjacentes é de média densidade.

No período correspondente ao inverno, o ponto P9 (R. Euclides da Cunha com R. Padre Agostinho - Bigorrilho) apresentou a menor temperatura máxima absoluta. A menor temperatura também pode ser relacionada ao sombreamento dos prédios, já que está localizado no Setor Especial Estrutural (SE), com muitos prédios altos e com alto fluxo de veículos, além de estar próximo de Zona Residencial de Média Densidade (ZR-3).

\section{Variação térmica no transecto noroeste-sudeste}

No transecto noroeste-sudeste, o ponto P3 (R. André de Barros com R. Barão do Rio Branco Centro), localizado em área central consolidada (Zona Central - ZC), altamente impermeabilizada e com grande circulação de veículos, com a maioria das construções com menos de seis pavimentos, destacou-se por apresentar os maiores valores de temperaturas média, mínima absoluta, média das máximas e mínimas diárias em todas as estações do ano e as maiores temperaturas máximas absolutas nos períodos correspondentes ao outono e ao inverno. A diferença desse ponto em relação aos de menor temperatura foi de $1,3{ }^{\circ} \mathrm{C}$ para a média das mínimas diárias e de $4,6^{\circ} \mathrm{C}$ para a mínima absoluta (Tabela 4), mostrando novamente o efeito de aquecimento das áreas urbanizadas e do calor antropogênico.

Para a variável temperatura mínima absoluta, a maior diferença térmica foi de $3,9{ }^{\circ} \mathrm{C}$ no período correspondente ao inverno (Tabela 4). Nesse período foram observadas temperaturas negativas de $-0,2{ }^{\circ} \mathrm{C}$ nos pontos P30 (R. José Valle - São João) e P34 (R. Salgado Filho com R. João Antonio Prosdócimo Jardim das Américas) e de $-0,6{ }^{\circ} \mathrm{C}$ no ponto P35 (R. Velci Bolívar Grando com R. Amauri Mauad Guérios - Uberaba), localizados nos extremos desse transecto, em áreas com menos impermeabilização. Já as maiores temperaturas mínimas ocorreram na área central, nos pontos P1 e P3.

Para a temperatura máxima absoluta, as diferenças extremas variaram de $2{ }^{\circ} \mathrm{C}$ no inverno a $4,1^{\circ} \mathrm{C}$ na primavera (Tabela 3), destacando-se pelas maiores temperaturas os pontos P5 (R. Inácio Lustosa com R. João Manoel - São Francisco) e P32 (R. Guabirotuba com R. Imaculada Conceição Prado Velho), ambos em Zona Residencial de Média Densidade (ZR-3). As maiores temperaturas máximas ocorreram nas áreas mais urbanizadas, porém menos verticalizadas.

Os resultados mostram a variação de temperatura de acordo com categorias de uso de solo e densidade de construções, assim como verificado por Bonan (2000), Pinho e Organs (2000), Svensson e Eliasson (2002), Faria e Mendes (2004), Gaffin et al. (2008), Huang et al. (2008) e Xiao et al. (2008).

Os menores valores de temperaturas médias, máximas absolutas, média das máximas e mínimas diárias ocorreram do lado noroeste do transecto, nos pontos P29 (R. Fredolin Wolf com R. Saturnino de Miranda - Lamenha Pequena), P30 (R. José Vale - São João) e P31 (R. Jacarezinho com R. Solimões Vista Alegre), em áreas residenciais de baixa densidade de ocupação e na região de Curitiba, que concentra a maior quantidade de cobertura vegetal, conforme Vieira e Biondi (2008).

\section{Variação térmica no transecto sudoeste-nordeste}

No transecto sudoeste-nordeste, as maiores temperaturas médias, mínimas absolutas e média das mínimas diárias ocorreram nos pontos P1 (Praça Tiradentes - Centro), P2 (R. Visconde de Nácar com R. Emiliano Perneta - Centro) e P4 (R. Luiz Leão com R. Conselheiro Araújo - Centro) (Tabela 5), localizados em Zona Central (ZC) e Zona Residencial de Média-Alta Densidade (ZR-4). 
Tabela 4. Temperaturas observadas no transecto noroeste-sudeste na cidade de Curitiba nos períodos correspondentes às estações do ano de 2011.

Table 4. Temperature observed in the northwest-south-east transect in the city of Curitiba, corresponding to the seasons of 2011.

\begin{tabular}{|c|c|c|c|c|c|c|c|c|c|c|c|}
\hline \multirow[b]{2}{*}{$\mathbf{P}$} & \multicolumn{10}{|c|}{ Pontos de monitoramento } & \multirow{2}{*}{ DT } \\
\hline & $\mathbf{P 2 9}$ & P30 & P31 & P5 & P1 & P3 & P32 & P33 & P34 & P35 & \\
\hline \multicolumn{12}{|c|}{ Temperatura média $\left({ }^{\circ} \mathrm{C}\right)$} \\
\hline $\mathrm{V}$ & $21,1 \pm 3,7$ & $20,9 \pm 3,6$ & $20,9 \pm 3,4$ & $21,9 \pm 3,8$ & $21,9 \pm 3,5$ & $22,5 \pm 3,9$ & $21,9 \pm 3,9$ & $21,6 \pm 3,6$ & $21,6 \pm 3,6$ & $21,8 \pm 3,8$ & 1,6 \\
\hline $\mathrm{O}$ & $14,1 \pm 4,2$ & $14,0 \pm 4,1$ & $14,3 \pm 3,8$ & $15,2 \pm 4,1$ & $15,3 \pm 3,8$ & $15,7 \pm 4,1$ & $15,2 \pm 4,4$ & $15,0 \pm 4,2$ & $14,8 \pm 4,1$ & $14,9 \pm 4,3$ & 1,7 \\
\hline I & $14,3 \pm 5,7$ & $14,1 \pm 5,8$ & $14,3 \pm 5,7$ & $14,9 \pm 5,8$ & $15,0 \pm 5,5$ & $15,5 \pm 5,9$ & $14,9 \pm 5,8$ & $14,8 \pm 5,8$ & $14,6 \pm 5,9$ & $14,5 \pm 5,8$ & 1,4 \\
\hline $\mathrm{P}$ & $17,5 \pm 5,1$ & $17,2 \pm 4,9$ & $17,2 \pm 4,7$ & $18,0 \pm 5,0$ & $18,3 \pm 4,9$ & $18,6 \pm 5,1$ & $18,1 \pm 5,1$ & $18,1 \pm 5,0$ & $17,9 \pm 5,0$ & $17,9 \pm 5,1$ & 1,5 \\
\hline \multicolumn{12}{|c|}{ Temperatura máxima absoluta $\left({ }^{\circ} \mathrm{C}\right)$} \\
\hline $\mathrm{V}$ & 32,8 & 31,9 & 31,9 & 34,9 & 33,2 & 34,4 & 34,4 & 33,6 & 33,6 & 33,6 & 2,9 \\
\hline $\mathrm{O}$ & 26,3 & 25,2 & 24,0 & 26,3 & 25,2 & 26,7 & 27,5 & 26,7 & 25,6 & 27,1 & 3,5 \\
\hline I & 29,5 & 29,5 & 29,5 & 30,3 & 29,9 & 31,5 & 30,3 & 31,1 & 31,1 & 30,7 & 2,0 \\
\hline $\mathrm{P}$ & 32,8 & 30,3 & 30,7 & 33,2 & 32,8 & 34,0 & 34,0 & 31,9 & 32,8 & 34,4 & 4,1 \\
\hline \multicolumn{12}{|c|}{ Temperatura mínima absoluta $\left({ }^{\circ} \mathrm{C}\right)$} \\
\hline $\mathrm{V}$ & 15,6 & 15,6 & 14,9 & 16,0 & 16,4 & 16,4 & 16,0 & 16,0 & 16,0 & 15,6 & 1,5 \\
\hline $\mathrm{O}$ & 2,5 & 3,3 & 5,0 & 6,2 & 6,6 & 7,0 & 4,6 & 5,4 & 4,6 & 3,3 & 4,6 \\
\hline I & 1,2 & $-0,2$ & 2,0 & 2,9 & 3,3 & 3,3 & 1,2 & 1,6 & $-0,2$ & $-0,6$ & 3,9 \\
\hline $\mathrm{P}$ & 8,2 & 7,8 & 8,6 & 9,8 & 9,0 & 9,8 & 9,4 & 9,4 & 9,0 & 9,4 & 2,0 \\
\hline \multicolumn{12}{|c|}{ Média das máximas diárias de temperatura $\left({ }^{\circ} \mathrm{C}\right)$} \\
\hline $\mathrm{V}$ & $27,9 \pm 3,9$ & $27,4 \pm 3,7$ & $26,9 \pm 3,7$ & $29,0 \pm 4,0$ & $28,5 \pm 3,1$ & $29,6 \pm 3,9$ & $28,8 \pm 4,1$ & $28,4 \pm 3,6$ & $28,4 \pm 3,6$ & $28,7 \pm 3,6$ & 2,7 \\
\hline $\mathrm{O}$ & $18,8 \pm 5,4$ & $18,1 \pm 5,2$ & $18,3 \pm 4,7$ & $19,9 \pm 5,0$ & $19,4 \pm 4,6$ & $20,5 \pm 5,1$ & $20,3 \pm 5,4$ & $19,9 \pm 5,3$ & $19,1 \pm 5,0$ & $19,7 \pm 5,2$ & 2,4 \\
\hline I & $20,8 \pm 6,5$ & $20,5 \pm 6,7$ & $20,0 \pm 6,4$ & $21,4 \pm 6,8$ & $20,8 \pm 6,2$ & $22,1 \pm 6,8$ & $21,4 \pm 6,7$ & $21,6 \pm 6,6$ & $21,8 \pm 6,6$ & $21,5 \pm 6,5$ & 2,1 \\
\hline $\mathrm{P}$ & $23,8 \pm 5,4$ & $23,0 \pm 5,0$ & $23,1 \pm 5,0$ & $24,0 \pm 5,4$ & $24,9 \pm 5,0$ & $25,0 \pm 5,3$ & $24,2 \pm 5,4$ & $24,4 \pm 5,0$ & $24,5 \pm 5,2$ & $24,5 \pm 5,2$ & 2,0 \\
\hline \multicolumn{12}{|c|}{ Média das mínimas diárias de temperatura $\left({ }^{\circ} \mathrm{C}\right)$} \\
\hline $\mathrm{V}$ & $17,6 \pm 1,1$ & $17,4 \pm 1,1$ & $17,5 \pm 1,2$ & $18,2 \pm 1,2$ & $18,4 \pm 1,2$ & $18,7 \pm 1,3$ & $18,2 \pm 1,3$ & $18,0 \pm 1,2$ & $18,0 \pm 1,2$ & $18,1 \pm 1,1$ & 1,3 \\
\hline $\mathrm{O}$ & $10,3 \pm 3,3$ & $10,3 \pm 3,2$ & $11,1 \pm 2,8$ & $11,6 \pm 2,8$ & $12,1 \pm 2,8$ & $12,3 \pm 2,8$ & $11,4 \pm 3,0$ & $11,5 \pm 2,9$ & $11,1 \pm 2,9$ & $11,0 \pm 3,0$ & 2,1 \\
\hline I & $9,7 \pm 4,2$ & $9,5 \pm 4,2$ & $9,9 \pm 3,9$ & $10,4 \pm 3,7$ & $10,7 \pm 3,8$ & $10,8 \pm 3,7$ & $10,0 \pm 3,7$ & $10,2 \pm 3,8$ & $9,7 \pm 3,9$ & $9,7 \pm 4,0$ & 1,3 \\
\hline $\mathrm{P}$ & $12,4 \pm 2,5$ & $12,3 \pm 2,5$ & $12,7 \pm 2,5$ & $13,4 \pm 2,4$ & $13,6 \pm 2,6$ & $13,8 \pm 2,6$ & $13,3 \pm 2,5$ & $13,3 \pm 2,5$ & $13,1 \pm 2,5$ & $13,0 \pm 2,4$ & 1,5 \\
\hline
\end{tabular}

A menor temperatura mínima absoluta $\left(-0,2^{\circ} \mathrm{C}\right)$ foi verificada no ponto P36 (R. Raul Pompeia com R. Ludovico Kaminski - Cidade Industrial de Curitiba), ponto extremo do lado sudoeste e próximo do Parque Caiuá (Tabela 5). Nas outras estações ocorreram as menores temperaturas mínimas absolutas nos pontos P38 (R. Carlos Klemtz - Portão), próximo ao Bosque da Fazendinha, e P44 (R. Estrada das Olarias com R. Arnaldo W. Gaensli - Santa Cândida), no limite nordeste, em região com maior quantidade de remanescentes florestais do que os demais pontos do transecto.

O ponto P36 (Rua Raul Pompeia com Rua Ludovico Kaminski - CIC), em Zona de Uso Misto (ZUM), com média densidade habitacional, de apoio residencial às zonas industriais e de serviços, além de apresentar a menor mínima absoluta no verão, apresentou a maior máxima absoluta no mesmo período. Apesar de estar localizado na área limítrofe desse transecto, esse ponto não está entre os de menor temperatura média, resultado da impermeabilização e menor presença de vegetação.

Para a temperatura máxima absoluta e média das máximas diárias de temperatura, verificou-se que os maiores valores, similarmente aos resultados já discutidos, não ocorreram na área central. As menores máximas absolutas ocorreram no ponto P2 (R. Visconde de Nácar com R. Emiliano Perneta Centro), em todas as estações do ano, provavelmente pelo efeito de sombreamento já discutido, e ainda no outono, no ponto P39 (R. Curupaitis com R. Ulisses Vieira - Santa Quitéria), que, apesar de estar em Zona Residencial de Média Densidade (ZR-3), está próximo a várias praças e jardinetes, e no ponto P44.

O ponto P40 (Avenida Sete de Setembro com Rua Castro Alves - Batel), também localizado em área verticalizada, não apresentou as maiores temperaturas máximas, apesar de as temperaturas serem altas.

A maior diferença para a temperatura máxima absoluta do $\operatorname{ar}\left(5,8^{\circ} \mathrm{C}\right)$ ocorreu entre o ponto $\mathrm{P} 38$ (Rua Carlos Klemtz - Portão), com maior valor, e o ponto P2 (Rua Visconde de Nácar com Rua Emiliano 
Perneta - Centro) (Tabela 5), que foi o que apresentou a menor temperatura máxima. Apesar de o ponto P38 estar localizado em bairro com alta densidade populacional, não era esperado que fosse o ponto de maior temperatura máxima nesse transecto, pela localização próxima do Bosque da Fazendinha. A explicação provável é a ausência de outras tipologias de florestas urbanas nesse bairro, tais como praças com árvores, jardinetes e arborização de ruas.

Tabela 5. Temperaturas observadas no transecto sudoeste-nordeste na cidade de Curitiba nos períodos correspondentes às estações do ano de 2011.

Table 5. Temperature in the south-west-northeast transect in the city of Curitiba, corresponding to the seasons of 2011.

\begin{tabular}{|c|c|c|c|c|c|c|c|c|c|c|c|c|c|}
\hline \multirow{2}{*}{$\mathbf{P}$} & \multicolumn{12}{|c|}{ Pontos de monitoramento } & \multirow{2}{*}{ DT } \\
\hline & P36 & P37 & P38 & P39 & $\mathbf{P 4 0}$ & $\mathbf{P 2}$ & P1 & P4 & P41 & $\mathbf{P 4 2}$ & $\mathbf{P 4 3}$ & P44 & \\
\hline \multicolumn{14}{|c|}{ Temperatura média $\left({ }^{\circ} \mathrm{C}\right)$} \\
\hline \multirow{2}{*}{ V } & 21,9 & 21,8 & 21,8 & 21,8 & 21,7 & 21,8 & 21,9 & 22,1 & 21,6 & 21,6 & 21,5 & 21,6 & \multirow{2}{*}{0,6} \\
\hline & $\pm 4,2$ & $\pm 3,7$ & $\pm 4,0$ & $\pm 3,7$ & $\pm 3,8$ & $\pm 3,2$ & $\pm 3,5$ & $\pm 3,9$ & $\pm 3,8$ & $\pm 3,8$ & $\pm 3,5$ & $\pm 4,1$ & \\
\hline \multirow{2}{*}{$\mathrm{O}$} & 15,0 & 15,2 & 15,0 & 14,9 & 15,1 & 15,1 & 15,3 & 15,1 & 14,6 & 14,9 & 14,7 & 14,2 & \multirow{2}{*}{1,1} \\
\hline & $\pm 4,5$ & $\pm 4,3$ & $\pm 4,2$ & $\pm 4,1$ & $\pm 4,2$ & $\pm 3,6$ & $\pm 3,8$ & $\pm 3,9$ & $\pm 4,2$ & $\pm 4,4$ & $\pm 4,1$ & $\pm 4,2$ & \\
\hline \multirow{2}{*}{ I } & 14,6 & 14,8 & 14,7 & 14,8 & 14,7 & 15,1 & 15,0 & 15,1 & 14,5 & 14,6 & 14,6 & 14,2 & \multirow{2}{*}{0,9} \\
\hline & $\pm 5,8$ & $\pm 5,9$ & $\pm 6,0$ & $\pm 5,8$ & $\pm 5,7$ & $\pm 5,5$ & $\pm 5,5$ & $\pm 5,9$ & $\pm 5,8$ & $\pm 5,9$ & $\pm 5,9$ & $\pm 5,9$ & \\
\hline \multirow{2}{*}{$\mathrm{P}$} & 18,2 & 18,4 & 18,3 & 18,2 & 18,0 & 17,9 & 18,3 & 18,6 & 17,6 & 17,9 & 17,6 & 17,9 & \\
\hline & $\pm 5,1$ & $\pm 5,4$ & $\pm 5,5$ & $\pm 5,0$ & $\pm 5,2$ & $\pm 4,5$ & $\pm 4,9$ & $\pm 5,3$ & $\pm 5,1$ & $\pm 5,1$ & $\pm 4,9$ & $\pm 5,4$ & 1,0 \\
\hline \multicolumn{14}{|c|}{ Temperatura máxima absoluta $\left({ }^{\circ} \mathrm{C}\right)$} \\
\hline $\mathrm{V}$ & 34,9 & 33,6 & 34,9 & 32,3 & 34,4 & 30,3 & 33,2 & 34,4 & 33,2 & 33,6 & 33,6 & 34,0 & 4,5 \\
\hline $\mathrm{O}$ & 26,7 & 26,0 & 26,3 & 25,2 & 27,1 & 25,2 & 25,2 & 25,6 & 26,7 & 27,5 & 25,6 & 25,2 & 2,4 \\
\hline I & 30,7 & 30,7 & 31,1 & 31,1 & 30,7 & 29,9 & 29,9 & 31,5 & 30,3 & 31,5 & 31,9 & 31,1 & 2,0 \\
\hline $\mathrm{P}$ & 33,6 & 34,0 & 35,7 & 32,8 & 34,4 & 29,9 & 32,8 & 34,4 & 33,2 & 33,2 & 31,9 & 35,3 & 5,8 \\
\hline \multicolumn{14}{|c|}{ Temperatura mínima absoluta $\left({ }^{\circ} \mathrm{C}\right)$} \\
\hline $\mathrm{V}$ & 15,2 & 15,6 & 15,2 & 15,6 & 15,6 & 16,0 & 16,4 & 16,4 & 15,6 & 16,0 & 16,0 & 15,6 & 1,2 \\
\hline $\mathrm{O}$ & 3,3 & 4,6 & 4,2 & 4,6 & 6,2 & 6,6 & 6,6 & 5,4 & 5,0 & 5,0 & 5,0 & 2,9 & 3,7 \\
\hline I & $-0,2$ & 1,6 & 1,2 & 1,2 & 2,5 & 3,3 & 3,3 & 2,9 & 1,2 & 1,6 & 2,0 & 1,2 & 3,5 \\
\hline $\mathrm{P}$ & 8,2 & 9,4 & 8,6 & 9,8 & 9,8 & 10,2 & 9,0 & 9,8 & 8,6 & 7,8 & 8,2 & 7,4 & 2,8 \\
\hline \multicolumn{14}{|c|}{ Média das máximas diárias de temperatura $\left({ }^{\circ} \mathrm{C}\right)$} \\
\hline \multirow{2}{*}{ V } & 29,8 & 28,9 & 29,5 & 28,4 & 28,8 & 26,9 & 28,5 & 28,9 & 28,9 & 28,8 & 27,7 & 28,8 & \multirow{2}{*}{2,9} \\
\hline & $\pm 4,1$ & $\pm 3,9$ & $\pm 3,9$ & $\pm 3,7$ & $\pm 3,9$ & $\pm 3,1$ & $\pm 3,1$ & $\pm 4,0$ & $\pm 3,7$ & $\pm 3,8$ & $\pm 3,7$ & $\pm 4,1$ & \\
\hline \multirow{2}{*}{$\mathrm{O}$} & 20,4 & 19,7 & 19,5 & 19,1 & 20,5 & 19,5 & 19,4 & 18,9 & 19,3 & 20,2 & 19,1 & 18,5 & \multirow{2}{*}{2,0} \\
\hline & $\pm 5,5$ & $\pm 5,0$ & $\pm 5,1$ & $\pm 5,0$ & $\pm 5,6$ & $\pm 3,9$ & $\pm 4,6$ & $\pm 4,7$ & $\pm 5,4$ & $\pm 5,6$ & $\pm 5,1$ & $\pm 5,0$ & \\
\hline \multirow{2}{*}{ I } & 21,5 & 21,3 & 21,2 & 21,3 & 21,4 & 20,8 & 20,8 & 22,0 & 21,0 & 21,5 & 21,0 & 20,9 & \multirow{2}{*}{1,2} \\
\hline & $\pm 6,7$ & $\pm 6,7$ & $\pm 6,8$ & $\pm 6,7$ & $\pm 6,8$ & $\pm 6,4$ & $\pm 6,2$ & $\pm 7,1$ & $\pm 6,6$ & $\pm 6,9$ & $\pm 7,0$ & $\pm 6,8$ & \\
\hline \multirow{2}{*}{$\mathrm{P}$} & 24,5 & 25,7 & 25,8 & 24,5 & 25,0 & 22,8 & 24,9 & 25,5 & 23,7 & 24,4 & 24,0 & 25,0 & \multirow{2}{*}{3,0} \\
\hline & $\pm 5,6$ & $\pm 5,5$ & $\pm 5,7$ & $\pm 5,3$ & $\pm 5,7$ & $\pm 4,4$ & $\pm 5,0$ & $\pm 5,6$ & $\pm 5,8$ & $\pm 5,3$ & $\pm 5,1$ & $\pm 6,0$ & \\
\hline \multicolumn{14}{|c|}{ Média das mínimas diárias de temperatura $\left({ }^{\circ} \mathrm{C}\right)$} \\
\hline $\mathrm{V}$ & 17,9 & 18,0 & 17,9 & 18,1 & 18,1 & 18,6 & 18,4 & 18,2 & 17,8 & 18,0 & 18,0 & 17,7 & 09 \\
\hline v & $\pm 1,2$ & $\pm 1,2$ & $\pm 1,3$ & $\pm 1,3$ & $\pm 1,3$ & $\pm 1,4$ & $\pm 1,2$ & $\pm 1,2$ & $\pm 1,3$ & $\pm 1,3$ & $\pm 1,3$ & $\pm 1,2$ & 0,9 \\
\hline & 10,9 & 11,3 & 11,2 & 11,3 & 11,8 & 12,2 & 12,1 & 11,7 & 11,0 & 11,1 & 11,1 & 10,6 & \\
\hline U & $\pm 3,1$ & $\pm 3,0$ & $\pm 3,0$ & $\pm 2,9$ & $\pm 2,7$ & $\pm 2,7$ & $\pm 2,8$ & $\pm 2,8$ & $\pm 3,1$ & $\pm 3,0$ & $\pm 3,0$ & $\pm 3,0$ & 1,7 \\
\hline I & 9,7 & 10,1 & 9,8 & 10,1 & 10,3 & 10,9 & 10,7 & 10,4 & 9,8 & 9,9 & 10,0 & 9,7 & \\
\hline 1 & $\pm 4,0$ & $\pm 4,2$ & $\pm 4,0$ & $\pm 4,1$ & $\pm 3,8$ & $\pm 3,7$ & $\pm 3,8$ & $\pm 3,7$ & $\pm 3,9$ & $\pm 3,7$ & $\pm 3,8$ & $\pm 3,7$ & 1,2 \\
\hline & 13,2 & 13,3 & 12,9 & 13,4 & 13,3 & 13,7 & 13,6 & 13,5 & 12,9 & 12,8 & 12,8 & 12,6 & \\
\hline $\mathrm{P}$ & $\pm 2,5$ & $\pm 2,4$ & $\pm 2,5$ & $\pm 2,5$ & $\pm 2,5$ & $\pm 2,4$ & $\pm 2,6$ & $\pm 2,4$ & $\pm 2,6$ & $\pm 2,6$ & $\pm 2,5$ & $\begin{array}{r} \pm 2,7 \\
\end{array}$ & 1,1 \\
\hline
\end{tabular}

P: período; V: verão; O: outono; I: inverno; P: primavera; DT: diferença térmica.

\section{CONCLUSÕES}

- Os resultados obtidos nesta pesquisa confirmaram a influência da densidade de construção estabelecida pelo zoneamento do uso do solo e da distribuição das florestas urbanas na variação das temperaturas na cidade de Curitiba. 
- As diferenças térmicas ocorreram em todas as estações do ano, inclusive no outono e inverno, relacionadas ao calor antropogênico.

- Para a temperatura média, a variação das diferenças térmicas foi de $0,6{ }^{\circ} \mathrm{C}$, no transecto sudoestenordeste no período do verão, a $1,7^{\circ} \mathrm{C}$ nos transectos norte-sul e noroeste-sudoeste no outono. Para a temperatura máxima absoluta, as diferenças foram de até $5,8^{\circ} \mathrm{C}$ no transecto sudoeste-nordeste na primavera, e para a temperatura mínima absoluta, de $4,6^{\circ} \mathrm{C}$ no transecto noroeste-sudeste no outono.

- As temperaturas foram elevadas nos locais com maior densidade de ocupação e calor antropogênico, porém as maiores temperaturas máximas não ocorrem nas áreas mais verticalizadas do centro e dos setores estruturais, mostrando o efeito do sombreamento de prédios. Já nos bairros periféricos ou residenciais com menor densidade de construção, maior quantidade de áreas permeáveis, concentração de remanescentes florestais ou espaços verdes públicos as temperaturas foram menores. Isso enfatiza a importância de ações municipais para manter e implantar diferentes tipologias de florestas urbanas em áreas públicas e particulares da cidade.

\section{AGRADECIMENTOS}

À Fundação Araucária de Apoio ao Desenvolvimento Científico e Tecnológico do Paraná, pelo financiamento desta pesquisa.

À URBS - Urbanização de Curitiba S.A., pela permissão da instalação dos miniabrigos meteorológicos nas estruturas urbanas.

\section{REFERÊNCIAS}

ANDRADE, H. O clima urbano - Natureza, escalas de análise e aplicabilidade. Finisterra, Lisboa, v. 40, n. 80, p. 67 - 91, 2005.

BLANCHET, I. V. R. P. Análise bioclimática dos parâmetros de conforto térmico humano e sua relação com os índices termo-higrométricos e a forma urbana do bairro Bigorrilho em Curitiba. 128 f. Dissertação (Mestrado em Geografia) - Universidade Federal do Paraná, Curitiba, 2004.

BONAN, G. B. The microclimates of a suburban Colorado (USA) landscape and implications for planning and design. Landscape and Urban Planning, Amsterdam, v. 49, p. 97 - 114, 2000.

DANNI-OLIVEIRA, I. M. A cidade de Curitiba e a poluição do ar: implicações de seus atributos urbanos e geoecológicos na dispersão de poluentes em período de inverno. $330 \mathrm{f}$. Tese (Doutorado em Geografia) - Universidade de São Paulo, São Paulo, 2000.

DUMKE, E. M. S. Clima urbano / conforto térmico e condições de vida na cidade - uma perspectiva a partir do aglomerado urbano da Região Metropolitana de Curitiba (AU-RMC). 417 f. Tese (Doutorado em Meio Ambiente e Desenvolvimento) - Universidade Federal do Paraná, Curitiba, 2007.

FARIA, J. R. G.; MENDES, J. F. G. Sobre o uso e ocupação do solo urbano e a temperatura do ar. Ambiente Construído, Porto Alegre, v. 4, n. 3, p. 7 - 17, 2004.

FEITOSA, S. M. R.; GOMES, J. M. A.; MOITA NETO, J. M.; ANDRADE, C. S. P. Consequências da urbanização na vegetação e na temperatura da superfície de Teresina, Piauí. Revista da Sociedade Brasileira de Arborização Urbana, Piracicaba, v. 6, n. 2, p. 58 - 75, 2011.

GAFFIN, S. R.; ROSENZWEIG, C.; KHANBILVARDI, R.; PARSHALL, L.; MAHANI, S.; GLICKMAN, H.; GOLDBERG, R.; BLAKE, R.; SLOSBERG, R. B.; HILLEL, D. Variations in New York city's urban heat island strength over time and space. Theoretical and Applied Climatology, v. 94, p. 1 11, 2008.

GONÇALVES, W; PAIVA, H. N. Silvicultura Urbana: implantação e manejo. Viçosa: Aprenda Fácil, 2006. $201 \mathrm{p}$.

HUANG, L. M.; LI, H. T.; ZHA, D. H.; ZHU, J. Y. A fieldwork study on the diurnal changes of urban microclimate in four types of ground cover and urban heat island of Nanjing, China. Building and Environment, Oxford, v. 43, p. 7 - 17, 2008. 
INSTITUTO DE PESQUISA E PLANEJAMENTO URBANO DE CURITIBA (IPPUC). Curitiba em dados. Disponível em: <http://ippucnet.ippuc.org.br/bancodedados/curitibaemdados/curitiba_em_dados_ pesquisa.asp>. Acesso em: 19/01/2012.

KING, V. J.; DAVIS, C. A case study of urban heat islands in the Carolinas. Environmental Hazards, Oxford, v. 7, p. 353 - 359, 2007.

KLYSIK, K.; FORTUNIAK, K. Temporal and spatial characteristics of the urban heat island of Lodz, Poland. Atmospheric Environment, Oxford, v. 33, p. 3885 - 3895, 1999.

LEAL, L. A influência da vegetação no clima urbano da cidade de Curitiba, PR. 172 f. Tese (Doutorado em Engenharia Florestal) - Universidade Federal do Paraná. Curitiba, 2012.

LEMOS, J. Espacialização da ilha de calor do aglomerado urbano da Região Metropolitana de Curitiba (AU-RMC) em agosto de 2006 a partir de termografia de superfície. In: SIMPÓSIO BRASILEIRO DE SENSORIAMENTO REMOTO - SBSR, 15., 2011, Curitiba. Anais... Curitiba, 2011. p. 4271 - 4278.

MENDONÇA, F. A.; DANNI-OLIVEIRA, I. M. Climatologia: noções básicas e climas do Brasil. São Paulo: Oficina de Texto, 2007. v. 1. 206 p.

MENDONÇA, F. A.; DUBREUIL, V. Termografia de superfície e temperatura do ar na RMC (Região Metropolitana de Curitiba / PR). R. Ra'ega, Curitiba, n. 9, p. 25 - 35, 2005.

MEMON, R. A.; LEUNG, D. Y. C.; CHUNHO, L. A review on the generation, determination and mitigation of Urban Heat Island. Journal of Environmental Sciences, Beijing, v. 20, p. 120 - 128, 2008.

MILLER, R. W. Urban Forestry: planning and managing urban greenspaces. 2. ed. New Jersey: Prentice-Hall, 1997. 502 p.

NOGAROLLI, M. Evolução climática do estado do Paraná: 1970 - 1999. 102 f. Dissertação (Mestrado em Geografia) - Universidade Federal do Paraná, Curitiba, 2007.

OKE, T. R. The distinction between canpoy layer and boundary-layer urban heat islands. Atmosphere, v. 14, n. 4, p. 268 - 277, 1976.

OLIVEIRA, S.; ANDRADE, H.; VAZ, T. The cooling effect of green spaces as a contribution to the mitigation of urban heat: A case study in Lisbon. Building and Environment, Oxford, v. 46, p. 2186 2194, 2011.

PINHO, O. S;-ORGAZ, M. D. M. The urban heat island in a small city in coastal Portugal. International Journal of Biometeorology, Milwaukee, v. 44, p. 198 - 203, 2000.

PREFEITURA MUNICIPAL DE CURITIBA. Áreas Verdes. 2011. Disponível em <http://www.curitiba. pr.gov.br/publico/secretaria.aspx ?idf=396\&servico=26>. Acesso em: 10/06/2011.

ROSSI, F. A. Análise da influência da ocupação do solo na variação de temperatura em diferentes localidades da cidade de Curitiba. 166 f. Dissertação (Mestrado em Tecnologia) - Centro Federal de Educação Tecnológica do Paraná, Curitiba, 2004.

SCHMITZ, L. K.; MENDONÇA, F. Reestruturação urbana e conforto térmico: cenários de modelização em Curitiba, PR, após a copa de 2014. Revista Brasileira de Climatologia, São Paulo, v. 8, n. 7, p. 61 81, 2011.

SVENSSON, M. K.; ELIASSON, I. Diurnal air temperatures in built-up areas in relation to urban planning. Landscape and Urban Planning, Amsterdam, v. 61, p. 37 - 54, 2002.

VIEIRA, C. H. S. D.; BIONDI, D. Análise da dinâmica da cobertura vegetal de Curitiba, PR (de 1986 a 2004), utilizando imagens Landsat TM. Árvore, Viçosa, v. 32, n. 3, p. 479 - 487, 2008.

WENG, Q.; LARSON, R. C. Satellite remote sensing of urban heat islands: current practice and prospects. In: JENSEN, R. R.; GATRELL, J. D.; McLEAN, D. D. Geo-spatial technologies in urban environments. New York: Springer, 2005. p. 91 - 111. 
WORLD METEOROLOGICAL ORGANIZATION. Guide to meteorological instruments and methods of observation. 7nd. Geneva: WMO, 2008. Disponível em: <http://www.wmo.int/pages/prog/ www/IMOP/publications/CIMO-Guide/CIMO_Guide-7th_Edition-2008.html>. Acesso em: 31/07/2009.

XIAO, R. B.; WENG, Q. H.; OUYANG, Z. Y.; LI, W. F.; SCHIENKE, W.; ZHANG, Z. M. Land surface temperature variation and major factors in Beijing, China. Photogram. Eng. Remote Sensing, v. 74, n. 4, p. 451 - 461, 2008.

YOUNG, A. F. Aplicação de índices relativos de vegetação e temperatura para estudo das mudanças do uso e ocupação do solo: estudo de caso de Curitiba (PR), 1986 a 2002. 100 f. Tese (Doutorado) - Universidade Estadual de Campinas, Campinas, 2005.

YOW, D. M.; CARBONE, G. J. The urban heat island and local temperature variations in Orlando, Florida. Southeastern Geographer, Athens, v. 46, n. 2, p. 297 - 321, 2006. 